\title{
Neoadjuvant Chemotherapy Improves Survival in Patients with Locally Advanced Nasopharyngeal Carcinoma
}

\author{
Hamit BASARAN ${ }^{1}$, Mustafa CENGIZ ${ }^{1}$, Gozde YAZICI ${ }^{1}$, Nilda SUSULU ${ }^{2}$, Sercan AKSOY ${ }^{3}$, \\ Ali Sefik HOSAL ${ }^{2}$, Ibrahim H. GULLU ${ }^{3}$, Gokhan OZYIGIT ${ }^{1}$ \\ ${ }^{1}$ Hacettepe University Faculty of Medicine, Department of Radiation Oncology \\ ${ }^{2}$ Hacettepe University Faculty of Medicine, Department of Otorhinolaryngology \\ ${ }^{3}$ Hacettepe University Faculty of Medicine, Department of Medical Oncology,
} Ankara, TURKEY

\begin{abstract}
This study aimed to evaluate survival in patients with locally advanced nasopharyngeal carcinoma. The records of 407 patients with locally advanced nasopharyngeal carcinoma treated retrospectively reviewed. Patients were treated with 5 different treatment protocols: $22.4 \%$ patients received radiotherapy, $16.4 \%$ received concomitant chemoradiotherapy, $11.3 \%$ received concomitant chemoradiotherapy + adjuvant chemotherapy, $30.7 \%$ received neoadjuvant chemotherapy + concomitant chemoradiotherapy, and $19.2 \%$ received neoadjuvant chemotherapy + radiotherapy. At the median follow-up of 64 months 5 -year and 10-year overall survival were $64.6 \%$ and $55.3 \%$, respectively, and 5-year and 10-year locoregional relapse-free survival were $58.5 \%$ and $49.2 \%$, respectively. Age $<40$ years $(p<0.001)$ and early stage $(p=0.014)$ were associated with better survival. Among the treatment protocols, neoadjuvant chemotherapy + radiotherapy yielded the best survival $(p=0.001)$. Concomitant chemoradiotherapy was not associated with any survival advantage; however, the addition of chemotherapy to concomitant chemoradiotherapy prolonged survival, regardless of radiotherapy schedule. The present findings show that the addition of chemotherapy, especially neoadjuvantly, improved overall survival.
\end{abstract}

Keywords: Nasopharyngeal Carcinoma, Neoadjuvant chemotherapy, Concomitant Chemoradiotherapy, Survival

\section{Neoadjuvan Kemoterapi, Lokal İleri Nazofaringeal Karsinomalı Hastalarda Sağkalımı İyileştirir}

Bu çalışmada lokal ileri nazofarengeal karsinomalı hastalarda sağkalımı değerlendirmeyi amaçladık. Lokal ileri nazofarengeal karsinomu olan 407 hastanın kayıtları retrospektif olarak incelendi. Hastalar 5 farklı tedavi protokolü ile tedavi edildi: hastaların \%22.4'ü radyoterapi, \%16.4'i eşzamanlı kemoradyoterapi, \%11.3'ü eşzamanlı kemoradyoterapi + adjuvan kemoterapi, \%30.7'si neoadjuvan kemoterapi + eşzamanlı kemoradyoterapi, \%19.2'si neoadjuvan kemoterapi + eşzamanlı kemoradyoterapi aldı. Ortanca 64 aylık izlemde, 5 ve 10 yıllık genel sağkalım sırasıyla \%64.6 ve \%55.3, 5 yıllık ve 10 yıllık local bölgesel nükssüz sağkalım sırasıyla \%58.5 ve \%49.2 idi. Erken evre $(p=0.014)$ ve 40 yaş altı hastalar $(p<0.001)$ daha iyi sağkalım ile ilişkiliydi. Tedavi protokolleri arasında neoadjuvan kemoterapi + radyoterapi en iyi sağkalımı vermiştir ( $p=0.001)$. Eş zamanlı kemoradyoterapi sağkalım avantajı sağlamamıştır, ancak kemoradyoterapiye kemoterapinin ilave edilmesi , radyoterapi programı ne olursa olsun sağkalım süresini uzatmıştır. Mevcut bulgular, özellikle neoadjuvan kemoterapinin eklenmesinin genel sağkalımı iyileştirdiğini göstermektedir.

Anahtar Kelimeler: Nasopharyngeal Carcinoma, Neoadjuvant chemotherapy, Concomitant Chemoradiotherapy, Survival

ORCIDS: Hamit Basaran: 0000-0002-2122-8720 Nilde Suslu: 0000-0002-2122-8720 Ibrahim Gullu: 0000-0002-2122-8720
Mustafa Cengiz: 0000-0002-2122-8720 Sercan Aksoy: 0000-0002-2122-8720 Gokhan Ozyigit: 0000-0002-2122-8720
Gozde Yazici: 0000-0002-2122-8720

Ali Sefik Hosal: 0000-0002-2122-8720 


\section{INTRODUCTION}

Nasopharyngeal carcinoma (NPC) is among the most frequently diagnosed head and neck squamous cell carcinomas (SCCs). ${ }^{1}$ The Surveillance, Epidemiology, and End Results Program reported that the incidence of NPC exhibits an extremely heterogenous geographic and ethnic distribution, which has been explained hitherto. ${ }^{2}$ Literature reviews emphasize the high incidence of NPC and report that worldwide there are 25/100.000 newly diagnosed cases annually, versus 2-4/100.000 in Turkey. ${ }^{3}$

A multidisciplinary approach to the treatment of NPC is essential. The place of surgical treatment is restricted with diagnosis and salvage treatments because of the higher risks of morbidity and mortality. ${ }^{4}$ Radiotherapy (RT) is the standard treatment approach. ${ }^{5}$ Studies on NPC patients with locally advanced disease have sought to determine if chemotherapy (CT) can improve local control and survival. ${ }^{6,7,8,9}$ Al-Sarraf et al.'s randomized intergroup study showed that chemoradiotherapy (CRT) followed by adjuvant cisplatin/5FU resulted in better overall survival (OS) and diseasefree survival (DFS) than RT only; however, $45 \%$ of patients in the CT arm of their study couldn't tolerate adjuvant CT (AdjCT) due to toxicity. ${ }^{7} \mathrm{Na}-$ tional Comprehensive Cancer Network (NCCN) determined new standard in NPC as CT arm based on the results and inclusion criteria of this study. ${ }^{10}$ Subsequently, neoadjuvant studies were performed instead of adjuvant studies and an increase in patient tolerance was noted. Based on these studies' findings, it was suggested that addition of neoadjuvant $\mathrm{CT}$ (NeoCT) to RT decreases the risk of recurrence and metastasis, but has no effect on survival. ${ }^{1}$ To the best of our knowledge the literature does not include any study comparing NeoCT and AdjCT in addition to CRT in patients with NPC. The present retrospective study aimed to compare the effectiveness and toxicity of NeoCT in addition to other treatment protocols in patients with locally advanced NPC and impact on survival.

\section{PATIENTS and METHODS}

The files of patients diagnosed between June 1994 and June 2011 as locally advanced NPC at Hac-

\begin{tabular}{|c|c|c|}
\hline \multirow[t]{2}{*}{ Characteristics } & \multicolumn{2}{|c|}{ Patients } \\
\hline & & $\%$ \\
\hline \multicolumn{3}{|l|}{ Gender } \\
\hline Male & 302 & 74 \\
\hline Female & 105 & 26 \\
\hline \multicolumn{3}{|l|}{ Age (years) } \\
\hline$<18$ & 55 & 13.5 \\
\hline $18-65$ & 324 & 79.6 \\
\hline$\geq 65$ & 28 & 6.9 \\
\hline \multicolumn{3}{|l|}{ Brachytherapy boost } \\
\hline Yes & 241 & 59.2 \\
\hline No & 166 & 40.8 \\
\hline \multicolumn{3}{|l|}{ RT Modality } \\
\hline Conventional & 393 & 96.5 \\
\hline 3D Conformal & 6 & 1.5 \\
\hline IMRT & 8 & 2.0 \\
\hline \multicolumn{3}{|l|}{ WHO Morphology } \\
\hline type 1 (keratinizing) & 18 & 4.5 \\
\hline type 2 (non-keratinizing) & 156 & 38.5 \\
\hline type 3 (undifferentiated) & 232 & 57 \\
\hline Not known (unspecified) & 1 & 0.2 \\
\hline \multicolumn{3}{|l|}{ External Radiotherapy Dose } \\
\hline$<6500$ cGy & 75 & 18.4 \\
\hline$\geq 6500$ cGy & 332 & \\
\hline \multicolumn{3}{|l|}{ TNM stage (AJCC, 7th Edition) } \\
\hline III & 203 & 50 \\
\hline IVA & 94 & 23 \\
\hline IVB & 110 & 27 \\
\hline \multicolumn{3}{|l|}{ Treatment Modality } \\
\hline RT & 91 & 22.4 \\
\hline CRT & 67 & 16.4 \\
\hline CRT + AdjCT & 46 & 11.3 \\
\hline $\mathrm{NeoCT}+\mathrm{CRT}$ & 125 & 30.7 \\
\hline $\mathrm{NeoCT}+\mathrm{RT}$ & 78 & 19.2 \\
\hline \multicolumn{3}{|c|}{ Chemotherapy (AdjCT or NeoCT) } \\
\hline Yes & 249 & 61.2 \\
\hline No & 158 & 38.8 \\
\hline \multicolumn{3}{|l|}{ Concomitant CRT } \\
\hline Yes & 238 & 58.5 \\
\hline No & 169 & 41.5 \\
\hline \multicolumn{3}{|c|}{$\begin{array}{l}\text { AJCC= American Joint Cancer Committee; RT= Radiotherapy; } \\
\text { IMRT= Intensity Modulated Radiotherapy; CRT= Chemoradiotherapy; } \\
\mathrm{CT}=\text { Chemotherapy; AdjCT= Adjuvant Chemotherapy; NeoCT= Neo- } \\
\text { adjuvant Chemotherapy }\end{array}$} \\
\hline
\end{tabular}

ettepe University, School of Medicine, Department of Radiation Oncology, Turkey, were retrospectively analyzed. The records of 407 patients with locally advanced NPC were selected from among 
those of 558 patients that were treated with definitive RT or CRT with or without AdjCT for inclusion in the study. Median duration of follow-up was 53 months (range $=3-324$ months).

Median patient age was 43 years (range $=9-82$ years); 302 (74\%) patients were male and 105 (26\%) were female. Clinical staging was based on MRI of the head and neck, thoracic and abdominal computed tomography, and whole-body bone scanning. Since 2007, most of the patients with distant metastasis were staged based on PET (18F-fluorodeoxy-glucose positron emission tomography)computed tomography. All patients were staged based on 2010 American Joint Cancer Committee (AJCC) TNM staging system guidelines (7th edition). Accordingly, 203 (50\%) patients were stage III, 94 (23\%) were stage Iva, and 110 (27\%) were stage IVb. Patient characteristics and treatment details are shown in Table 1.

All procedures performed were in accordance with the ethical standards of the institutional and/or national research committee and with the 1964 Helsinki Declaration and its later amendments or comparable ethical standarts. Informed consent was obtained from all participants included in the study.

\section{Treatments}

All patients were treated with daily fractions of 1.8-2.12 Gy (median: $2 \mathrm{~Gy}$ ). In each case the primary disease site received 60-70 Gy. Among the patients, 241 (59\%) received brachytherapy (BRT) boost. The median duration of RT was 52 days (range: $30-73 \mathrm{~d}$ ). The following treatments were administered: RT: $\mathrm{n}=91$ (22.4\%); concurrent CRT: $\mathrm{n}=67$ (16.4\%); CRT + AdjCT: $\mathrm{n}=46$ (11.3\%); NeoCT + CRT: $\mathrm{n}=125$ (30.7\%); NeoCT + RT: $\mathrm{n}=$ $78(19.2 \%)$. In the patients that received CRT the most frequently used concurrent single agent was platin-based (cisplatin or carboplatin). Use of concomitant cisplatin was recommended for 7 weeks (25-40 mg/week). Platin-based combinations (docetaxel and 5-FU) were used for the NeoCT and AdjCT protocols.

During the course of treatment, RT was administered using 3 different techniques: conventional $\mathrm{RT}$, three-dimensional conformal RT (3D-CRT), and intensity modulated radiation therapy (IMRT). BRT was used for boost doses in combination with external RT in patients with locally persistent tumors. Intracavitary BRT was administered at a total dose of 12 Gy (4 Gy 3/ fx) after external RT. BRT was performed using a high-dose rate (HDR) MicroSelectron device (Netherlands), an Ir-192 source, and special single channel applicators.

\section{Statistical Analysis}

Univariate and multivariate survival analysis (OS, DFS, locoregional recurrence-free survival [LRRFS], and distant metastasis-free survival [DMFS]) was performed. For PFS, such criteria as recurrence, progression, second primary cancer, and death were taken into consideration. The Kaplan-Meier method was used for survival analysis, the log-rank test was used for univariate analysis, and the Cox regression test was used for multivariate analysis. The effects of patient characteristics, tumor characteristics, and treatment protocols on prognosis were investigated. Data were analyzed using SPSS v.15.0 for Windows (SPSS, Inc., Chicago, IL). Categorical variables are shown as frequency and numerical variables are shown as descriptive statistics. Intergroup comparison of categorical variables was performed via cross-table statistics and the chi-square test was used to determine the level of significance. The Mann-Whitney $\mathrm{U}$ test was used for data not normally distributed. All tests were two-way and the level of statistical significance was set at $\mathrm{p}<0.05$.

\section{RESULTS}

At the last follow-up 227 (55.8\%) patients were alive with no evidence of disease, 18 (4.4\%) were alive with locally recurrent (LR) disease, and 8 (2\%) were alive with distant metastasis (DM). During follow-up 154 (37.8\%) patients died: 133 died due to disease recurrence, $15(3.7 \%)$ due to treatment toxicity, and 5 (1.2\%) due to non-tumorrelated causes. The cause of death in 1 patient was unknown.

The 2-year, 5-year, and 10-year OS rates were $82 \%, 65 \%$, and $55.3 \%$, respectively. The OS rate was higher among the female patients $(\mathrm{p}=0.002)$, 
International Journal of Hematology and Oncology

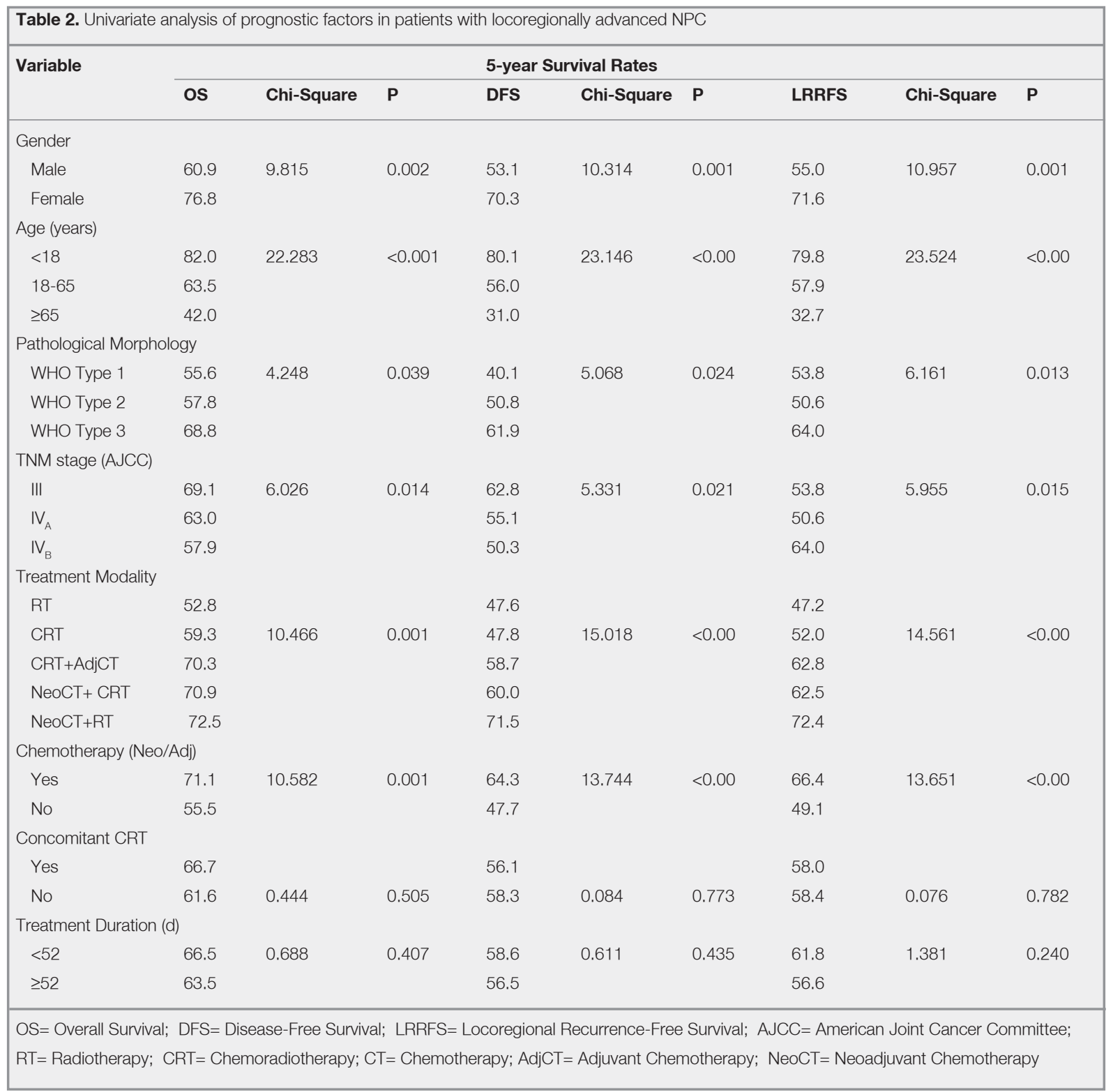

younger age group $(\mathrm{p}<0.001)$, stage III patients $(\mathrm{p}=0.014)$, those with WHO type 3 histopathology $(p=0.039)$, and patients treated with CT $(\mathrm{NeoCT}$ and AdjCT) $(p=0.001)$. The use of CRT + NeoCT and CRT + Adj CT did not yield better outcomes than RT + AdjCT or RT + NeoCT. The results of univariate analysis are summarized in Table 2.

Patients in the RT and CRT arms had significantly lower OS rates $(p=0.001)$, whereas the OS rate was similar in the other treatment groups (Figure 1). According to treatment groups, 5-year OS rates were as follows: RT: $52.8 \%$; CRT: $59.3 \%$; CRT + AdjCT: $70.3 \%$; NeoCT + CRT: 70.9\%; NeoCT +
RT: $72.5 \%$. The 2-year, 5-year, and 10-year DFS rates were $68.8 \%, 57.5 \%$, and $48 \%$, respectively. On the other hand, the use of different combinations of Platinum-based chemotherapeutic agent did not show any statistically significant difference in survival. Radiation therapy was applied using conventional planning to $96.5 \%$ (393 patients), 3D-CRT planning to $1.5 \%$ (6 patients) and IMRT to $2.0 \%$ (8 patients). Estimated OS for treatment modality did not show any statistically significant difference on OS. Multivariate analysis showed female gender $(\mathrm{p}=0.014)$, younger age $(\mathrm{p}<0.001)$, stage III disease $(\mathrm{p}=0.001)$, WHO type III his- 
International Journal of Hematology and Oncology

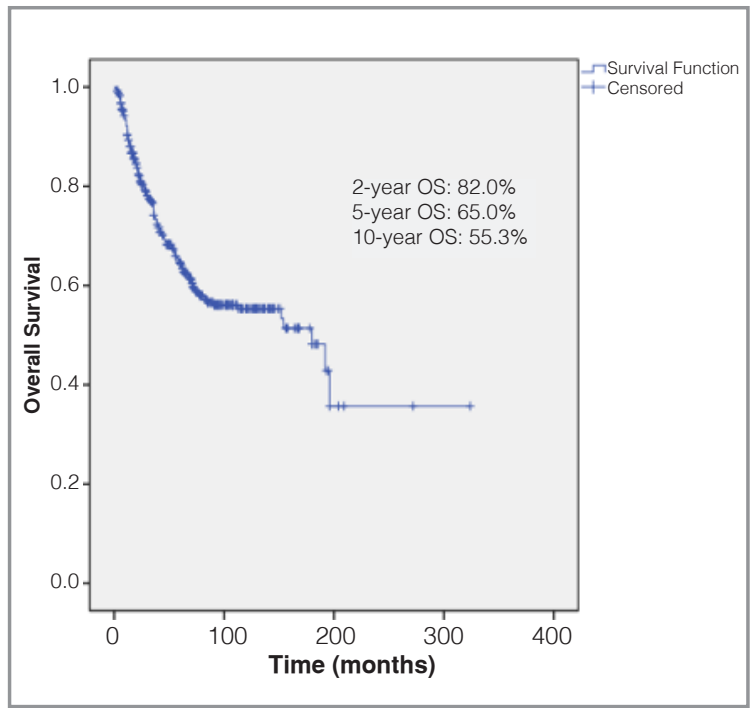

A.Overall Survival curve

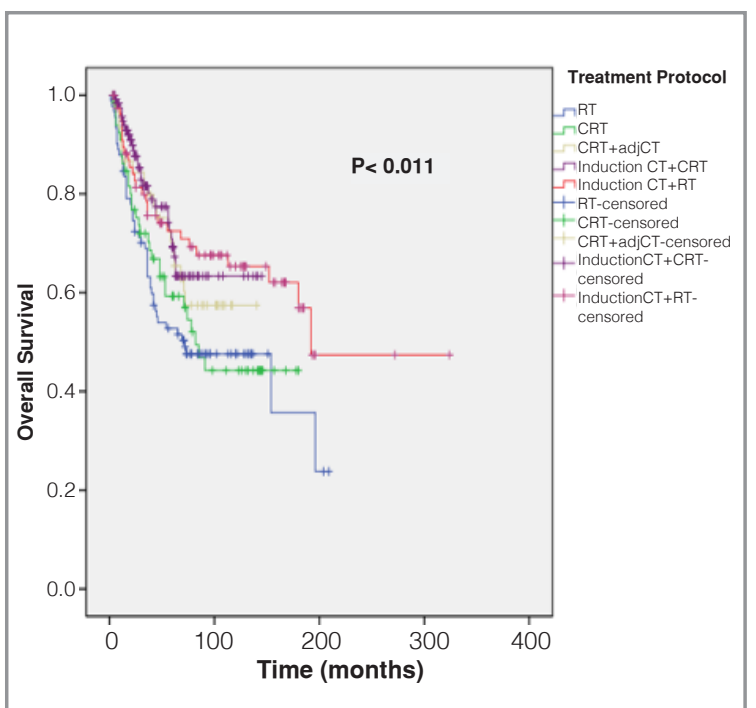

B. Survival curve according to treatment protocol

Figure 1. Overall Survival in 407 patients with locoregionally advanced NPC

topathology $(\mathrm{p}=0.015)$, and CT (NeoCT and AdjCT) in addition to RT $(p<0.001)$ were significant factors for DFS. Multivariate analysis results are shown in Table 3 and Figure 2.

\section{Locoregional Recurrence-Free Survival}

The 2-year, 5-year, and 10-year LRRFS rates were $74.1 \%, 59.2 \%$, and $49.2 \%$, respectively. At the last follow-up 18 (4.4\%) patients were alive with locoregional recurrence. Multivariate analysis

\begin{tabular}{|c|c|c|c|c|c|c|}
\hline \multirow{2}{*}{$\begin{array}{l}\text { Analysis data/ } \\
\text { Variant }\end{array}$} & \multicolumn{2}{|l|}{ os } & \multicolumn{2}{|l|}{ DFS } & \multicolumn{2}{|l|}{ LRRFS } \\
\hline & $\begin{array}{l}\text { HR } \\
(95 \% \mathrm{Cl})\end{array}$ & $\mathbf{P}$ & $\begin{array}{l}\text { HR } \\
(95 \% \mathrm{Cl})\end{array}$ & $\mathbf{P}$ & $\begin{array}{l}\text { HR } \\
(95 \% \mathrm{Cl})\end{array}$ & $\mathbf{P}$ \\
\hline \multicolumn{7}{|l|}{ Gender } \\
\hline (female vs. male) & $\begin{array}{l}0.580 \\
(0.380-0.887)\end{array}$ & 0.012 & $\begin{array}{l}0.621 \\
(0.424-0.909)\end{array}$ & 0.014 & $\begin{array}{l}0.630 \\
(0.424-0.936)\end{array}$ & 0.022 \\
\hline \multicolumn{7}{|l|}{ Age (years) } \\
\hline (<18 VS. $18-65$ VS. $\geq 65)$ & $\begin{array}{l}2.414 \\
(1.600-3.642)\end{array}$ & $<0.000$ & $\begin{array}{l}2.101 \\
(1.452-3.041)\end{array}$ & $<0.00$ & $\begin{array}{l}1.684 \\
(1.156-2.453)\end{array}$ & 0.007 \\
\hline $\begin{array}{l}\text { WHO Morphology } \\
\text { (type III vs. others) }\end{array}$ & $\begin{array}{l}0.749 \\
(0.573-0.977)\end{array}$ & 0.033 & $\begin{array}{l}0.729 \\
(0.565-0.941)\end{array}$ & 0.015 & $\begin{array}{l}0.874 \\
(0.673-1.135)\end{array}$ & 0.314 \\
\hline $\begin{array}{l}\text { TNM stage (AJCC) } \\
\text { (III vs. IVa-IVb) }\end{array}$ & $\begin{array}{l}1.367 \\
(1.127-1.658)\end{array}$ & 0.002 & $\begin{array}{l}1.342 \\
(1.122-1.604)\end{array}$ & 0.001 & $\begin{array}{l}1.321 \\
(1.106-1.576)\end{array}$ & 0.002 \\
\hline \multicolumn{7}{|l|}{$\begin{array}{l}\text { Treatment Modality } \\
\text { (Neo/Adj CT) }\end{array}$} \\
\hline (yes VS. no) & $\begin{array}{l}0.889 \\
(0.815-0.971)\end{array}$ & 0.009 & $\begin{array}{l}0.867 \\
(0.801-0.938)\end{array}$ & $<0.000$ & $\begin{array}{l}0.846 \\
(0.780-0.917)\end{array}$ & $<0.000$ \\
\hline
\end{tabular}




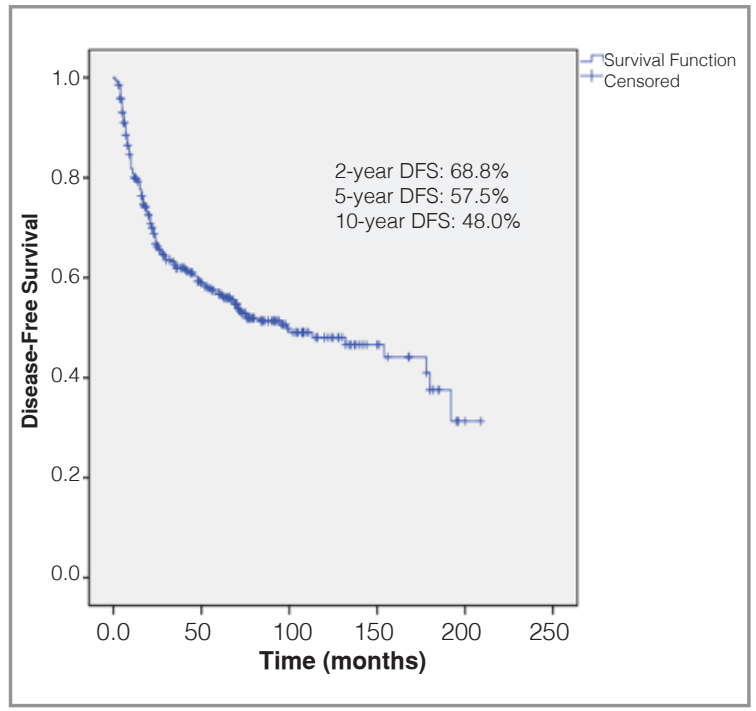

A. DFS curve

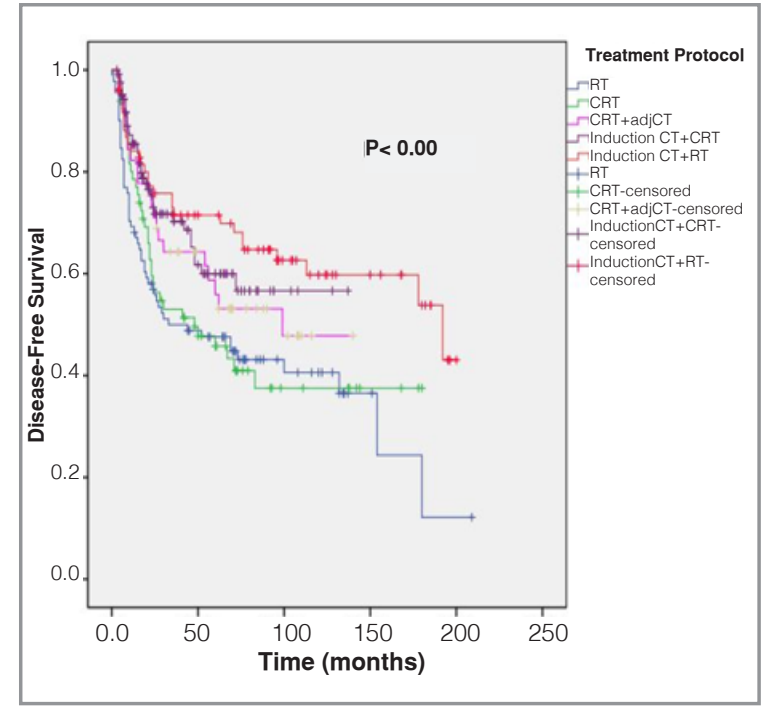

B. DFS curve according to treatment protocol

Figure 2. DFS curves for 407 patients with locoregionally advanced NPC

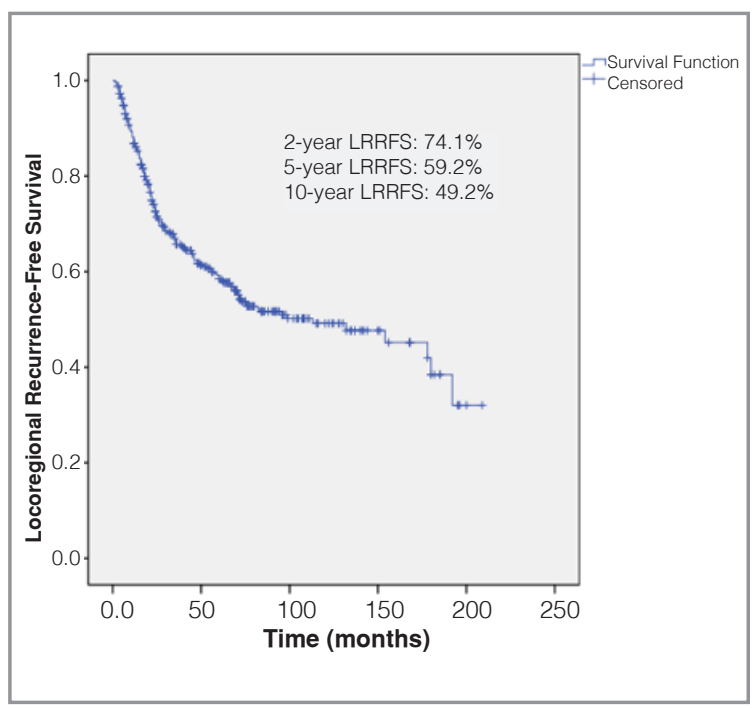

A. LRRFS curve

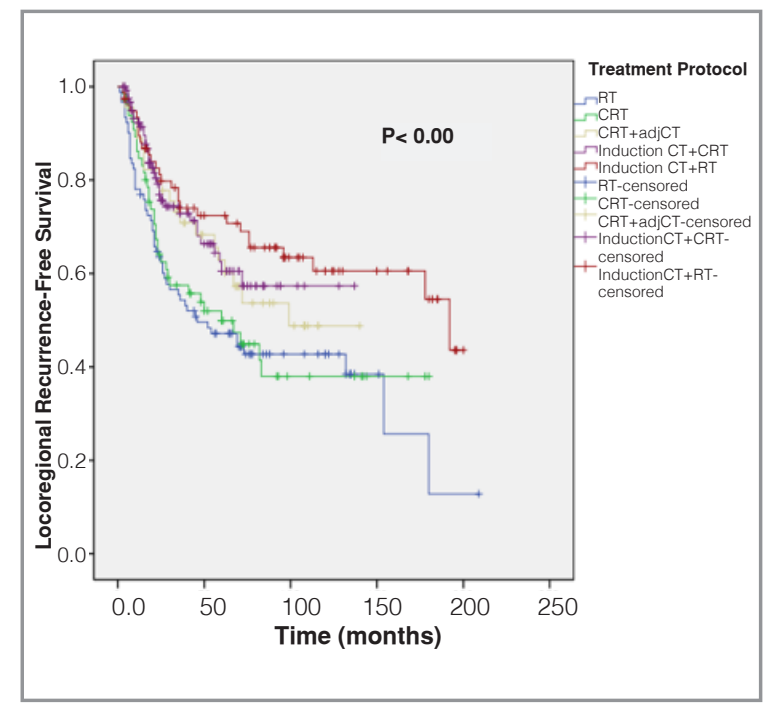

B. LRRFS curve according to treatment protocol

Figure 3. LRRFS curves of 407 patients with locoregionally advanced NPC

showed that female gender $(\mathrm{p}=0.022)$, younger age $(p=0.007)$, stage III disease $(p=0.002)$, and $\mathrm{CT}$ (NeoCT and AdjCT) in addition to RT ( $\mathrm{p}<$ $0.001)$ were significant factors for LRRFS. The results of multivariate analysis are summarized in Table 3 and Figure 3.

\section{Distant Metastasis-Free Survival}

The 2-year, 5-year, and 10-year DMFS rates were $75.7 \%, 62 \%$, and $52.6 \%$, respectively. Based on multivariate analysis, 2-year, 5-year, and 10-year DMFS rates differed significantly according to gender $(p=0.025)$, age group $(p<0.001)$, disease stage $(\mathrm{p}=0.001)$, and treatment protocol $(\mathrm{p}=0.002)$.

\section{Toxicity}

Late serious complications occurred in 91 (22\%) patients during follow-up, of which 14 (3.4\%) died due to treatment-related complications. In total, 12 (3\%) patients died due to poor performance sta- 


\begin{tabular}{|lll|}
\hline Table 4. Late toxicity & & \\
\hline Complication & $\mathbf{n}$ & $\%$ \\
\hline Xerostomia (grade I-III) & 235 & 57.7 \\
Hearing loss & 41 & 10.0 \\
Trismus & 12 & 2.9 \\
Optic neuropathy & 11 & 2.7 \\
Neck Fibrosis & 7 & 1.8 \\
Osteoradionecrosis & 7 & 1.8 \\
Inermitte's sign & 5 & 1.2 \\
Brain Necrosis & 5 & 1.2 \\
Hypothyroidism & 4 & 1.0 \\
Bleeding & 1 & 0.2 \\
Total & 328 & 80.5 \\
\hline
\end{tabular}

tus and infections, and $1(0.2 \%)$ patient died due to bleeding. The most frequent late toxicity was hearing loss, which occurred in $41(10 \%)$ patients. Other toxicities were trismus $(n=12[2.9 \%])$ and optic neuropathy ( $\mathrm{n}=11$ [2.7\%]). Complication details are summarized in Table 4.

The occurrence of toxicity was significantly higher in the CRT + AdjCT group (43\%) $(\mathrm{p}=0.033)$ than in the other treatment protocol groups. Hearing loss was the most frequent toxicity and occurred at a significantly higher rate in the CRT+ AdjCT group $(\mathrm{p}<0.001)$. When the effects of treatment modality on toxicity were evaluated, no statistically significant difference was found between this method. In total, 13 patients developed a second primary cancer during follow-up (lung, skin SCC, prostate, tonsil, larynx, base of the tongue, bladder, rectum, sarcoma, and lymphoma).

\section{DISCUSSION}

The main finding of the present retrospective study is that $\mathrm{NeoCT}+\mathrm{RT}$ resulted in better survival and less toxicity in patients with locally advanced NPC than did the other treatment protocols. Survival rates in the NeoCT + RT group were better perhaps due to avoidance of the side effects of concomitant treatment, as compared to those that received CRT.

The use of CT became standard for locally advanced NPC treatment following publication of the pivotal Intergroup 099 (IG-099) trial. In that randomized study 70-Gy standard RT only, and combined treatment concomitant and adjuvant CT with same radiotherapy protocol. Both 5-year DFS $(29 \%$ vs. $58 \%, \mathrm{p}<0.000)$ and OS $(37 \%$ vs. $67 \%, \mathrm{P}$ $=0.005$ ) were significantly higher in the combined modality treatment arm. ${ }^{7}$ Later, Lee et al. published their Hong Kong NPC 9901 study, which had a design similar to that of the IG-099 study. ${ }^{11}$ They reported that local control ( $82 \%$ vs. $93 \%, p=0.01)$ was significantly better in the combined arm, but that the difference had no effect on OS. The Meta-Analysis of Chemotherapy in Nasopharyngeal Carcinoma (MAC-NPC) Collaborative Group analyzed 1834 patients in 7 trials; the primary comparison was concomitant CRT versus RT only. ${ }^{12}$ It was reported that 10-year OS and DFS rates were significantly higher in the combined treatment group (10-year OS was $58.7 \%$ vs. $50.5 \%$, and 10 -year DFS was $51.8 \%$ vs. $44.3 \%$ ). In the present study concomitant CRT was not observed to be superior to RT only in the presence of AdjCT and NeoCT.

The benefit of AdjCT was studied in a Chinese phase III trial of 508 patients with locally advanced NPC. ${ }^{13}$ The patients were randomized into 2 arms: 1. AdjCT (cisplatin + 5-FU) after concurrent CRT with weekly cisplatin; 2 . Concurrent CRT only. At a median follow-up of 38 months there wasn't a significant difference in 2-year-failure-free survival (86\% vs. $84 \%$; respectively, HR: $0.74 ; 95 \% \mathrm{CI}$ : 0.49-1.10); however, another MAC-NPC study analyzed 1267 patients in 6 trials and observed some benefit of AdjCT. They compared concomitant CRT + AdjCT and RT only without concomitant or AdjCT. Although they reported that concurrent CRT followed by AdjCT might improve disease control, the benefit of more intensive therapy might be negated by death due to late toxicity. The addition of concurrent and AdjCT significantly reduced the disease-specific death rate ( $24 \%$ vs. $38 \%$ respectively,) and increased the death rate due to treatment-related toxicity in the CRT group, resulting in similar OS rates in the 2 groups (5-year OS was $68 \%$ vs. $64 \%$; respectively, HR: $0.81 ; 95 \%$ CI: $0.58-1.13) .{ }^{14}$ In the present study the percentage of patients with toxicity in the AdjCT arm was higher than in the other treatment arms, and was highest in the combined CRT + AdjCT group. Late 
serious complications were observed in $22 \%$ of the present study's patients and $3.4 \%$ died due to treatment-related complications. The most serious toxicity was noted in the concomitant CRT + AdjCT group $(43 \%)(\mathrm{p}=0.033)$.

The role of NeoCT followed by RT alone or concurrent CRT remains unclear. In a phase II study Lin et al. initially administered NeoCT via weekly doses of cisplatin $60 \mathrm{mg} / \mathrm{m}^{2}$, alternating with 5-fluorouracil $2500 \mathrm{mg} / \mathrm{m}^{2}+$ leucovorin $250 \mathrm{mg} /$ $\mathrm{m}^{2}$ for 10 weeks for NPC patients. ${ }^{15}$ After a week end CT One week later the patients received RT followed by weekly doses of AdjCT (cisplatin 25 $\mathrm{mg} / \mathrm{m}^{2}+5-\mathrm{FU} 1250 \mathrm{mg} / \mathrm{m}^{2}+$ bleomycin $10 \mathrm{mg} /$ $\mathrm{m}^{2}+$ leucovorin $120 \mathrm{mg} / \mathrm{m}^{2}$ ) for 10 weeks. With this regimen the researchers achieved treatment outcomes with less toxicity and most of the patients were received planned treatment. The International Nasopharynx Study Group (VUMCA-1) investigated the benefit of $\mathrm{NeoCT}$ and reported that in the CT-RT group treatment-related deaths more frequently in CT+RT arm. ${ }^{16}$ In their CT + RT arm the 5 year-DFS rate was significantly higher than in the CT only arm $(39 \%$ vs. $30 \%)(\mathrm{p}<0.01)$; however, the OS rates were similar. The Japon-91 study by Chua et al. randomized 80 patients into RT only and neoadjuvant cisplatin +5 -FU followed by RT arms. ${ }^{17}$ In the neoadjuvant arm both DFS and OS were better, but not significantly. Similarly, in the neoadjuvant study performed by The Asian-Oceanian Clinical Oncology Association Study Group during 30 months of median follow-up a trend towards improvement was observed in the neoadjuvant treatment group. ${ }^{6}$ In the Guangzhou-93 study performed by Hareyama et al. the RT only arm was compared to the 2-3 courses of neoadjuvant cisplatin, bleomycin, and 5-FU followed by RT arm, and 5-year DFS was significantly better in the CT arm (55\% vs. $43 \%) .{ }^{18}$ In an updated combined analysis of the previous 2 studies mentioned 789 patients were evaluated for a mean 67 months. ${ }^{19}$ It was noted that 5-year and 7-year DFS were significantly higher in patients that received CT (51\% vs. $43 \%$ and $49 \%$ vs. $37 \%$, respectively), but the difference in 5-year OS between treatments was not significant ( $62 \%$ vs. $58 \%$ ); however, distant metastasis control, and local control were significantly better in the $\mathrm{CT}$ arm. In the above-mentioned stud- ies NeoCT before RT resulted in better local control and DFS.

The MAC-NPC meta-analysis on the effect of NeoCT on treatment outcome included 6 randomized phase III studies and 1039 patients. ${ }^{20}$ The study reported that NeoCT only improves PFS (5-year PFS: $47 \%$ vs. $39 \%$ ) and has no effect on OS; however, NeoCT is tolerated to a greater degree and dose intensity achieved is greater, as compared to . As such, some experts recommend sequential therapy for large primary tumors and advanced nodal disease, or when delivery of full-dose RT is not possible because the tumor is surrounding critical structures. ${ }^{21}$ In the present study patients tolerated NeoCT followed by RT better than the other treatments and survival in the patients that received $\mathrm{Ne}$ oCT was similar to that in those that received other CT regimens.

NPC is more common in males; the male-female ratio is 3:1 and the prognosis of NPC is slightly better in females. ${ }^{22}$ The gender ratio in the present study is consistent with the literature, and median OS, DFS, and LRRFS were significantly better in the female patients. Age distribution demonstrates two peaks in low-risk populations both between 15-25 and 50-59 ages. ${ }^{23}$ In high-risk populations the incidence of NPC increases after age 30 years and peaks at age 40-60 years. Median age of the NPC patients in the present study (43 years) is also consistent with the literature. ${ }^{24,25}$ Among the present study's 3 age groups, the young age group had the best OS rate $(\mathrm{p}<0.001)$; in the present study the OS rate decreased with age.

Recent studies have shown that the NPC histopathological subtype is an important prognostic factor in endemic regions. WHO type 1 and WHO type 3 undifferentiated cancers are seen in younger patients, and are associated with Epstein-Barr virus infection and a better prognosis, as compared to WHO type $1 .{ }^{26}$ Based on the study data, WHO type 3 undifferentiated cancers are associated with better OS $(\mathrm{p}=0.039)$, DFS $(\mathrm{p}=0.015)$, and LRRFS $(\mathrm{p}=0.013)$ rates.

Survival analysis based on disease stage showed that OS in stage III patients was significantly better than in those with stage IVa and IVb, independent of other factors $(p=0.014)$. In patients with lo- 
cally advanced NPC, RT only is not sufficient for achieving disease control and is associated with a poor prognosis; therefore, combined CT and RT regimens are being used in an effort to improve disease prognosis.

\section{CONCLUSION}

The present findings show that age, disease stage, and treatment protocol are independent prognostic factors for survival in cases of locoregionally advanced NPC. NeoCT + RT significantly improves OS, with a lower rate of treatment-related adverse events in patients with locoregionally advanced NPC, as compared to other treatment protocols. Based on these findings, we hypothesize that omission of concomitant CT might be possible and that an effective alternative for achieving disease control could be sequential NeoCT $+\mathrm{RT}$. The major limitation of the present study is its retrospective design and distribution over a long period of time. Additional prospective randomized clinical trials are necessary to clearly determine the optimal combination of CT and RT.

\section{REFERENCES}

1. He X, Xu K, Guo J, et al. A meta-analysis of neoadjuvant chemotherapy plus radiation in the treatment of locallyadvanced nasopharyngeal carcinoma. J Cancer Res Ther 2: 205-208, 2015.

2. Black RJ, Bray F, Ferlay J, et al. Cancer incidence and mortality in the European Union: cancer registry data and estimates of national incidence for 1990. Eur J Cancer 33: 1075-107, 1997.

3. Yu MC, Yuan JM, et al. Epidemiology of nasopharyngeal carcinoma. Semin Cancer Biol 12: 421-429, 2002.

4. Wei WI, Cancer of the nasopharynx: functional surgical salvage. World J Surg 27: 844-848, 2003.

5. Yi JL, Gao L, Huang XD, et al. Nasopharyngeal carcinoma treated by radical radiotherapy alone: Ten-year experience of a single institution. Int J Radiat Oncol Biol Phys 65: 161-168, 2006.

6. Chua DT, Sham JS, Choy D, et al. Preliminary report of the Asian-Oceanian Clinical Oncology Association randomized trial comparing cisplatin and epirubicin followed by radiotherapy versus radiotherapy alone in the treatment of patients with locoregionally advanced nasopharyngeal carcinoma. Asian-Oceanian Clinical Oncology Association Nasopharynx Cancer Study Group. Cancer 83: 2270-2283, 1998.
7. Al-Sarraf M, LeBlanc M, Giri PG, et al. Chemoradiotherapy versus radiotherapy in patients with advanced nasopharyngeal cancer: phase III randomized Intergroup study 0099. J Clin Oncol 16: 1310-1317, 1998.

8. Cooper JS, Lee H, Torrey M, et al. Improved outcome secondary to concurrent chemoradiotherapy for advanced carcinoma of the nasopharynx: preliminary corroboration of the intergroup experience. Int J Radiat Oncol Biol Phys 47: 861 $866,2000$.

9. Chan AT, Teo PM, Leung TW, et al. A prospective randomized study of chemotherapy adjunctive to definitive radiotherapy in advanced nasopharyngeal carcinoma. Int J Radiat Oncol Biol Phys 33: 569-577, 1995.

10. National Comprehensive Cancer Network (NCCN) guidelines. Available at: www.nccn.org

11. Lee AW, Lau WH, Tung SY, et al. Preliminary results of a randomized study on therapeutic gain by concurrent chemotherapy for regionally-advanced nasopharyngeal carcinoma. J Clin Oncol 23: 6966-6975, 2005.

12. Blanchard P, Lee A, Marguet S, et al. Chemotherapy and radiotherapy in nasopharyngeal carcinoma: an update of the MAC-NPC meta-analysis. Lancet Oncol 16: 645-655, 2015.

13. Chen L, Hu CS, Chen XZ, et al. Concurrent chemoradiotherapy plus adjuvant chemotherapy versus concurrent chemoradiotherapy alone in patients with locoregionally advanced nasopharyngeal carcinoma: a phase 3 multicentre randomised controlled trial. Lancet Oncol 13: 163-171, 2012.

14. Lee AW, Tung SY, Chua DT, et al. Randomized trial of radiotherapy plus concurrent-adjuvant chemotherapy vs radiotherapy alone for regionally advanced nasopharyngeal carcinoma. J Natl Cancer Inst 102: 1188-1198 , 2010.

15. Lin JC, Jan JS, Hsu CY, et al. Outpatient weekly neoadjuvant chemotherapy followed by radiotherapy for advanced nasopharyngeal carcinoma: high complete response and low toxicity rates. Br J Cancer 88: 187-194, 2003.

16. International Nasopharynx Cancer Study Group. VUMCA I trial. Preliminary results of a randomized trial comparing neoadjuvant chemotherapy (cisplatin, epirubicin, bleomycin) plus radiotherapy vs. radiotherapy alone in stage $\mathrm{IV}(>$ or $=\mathrm{N} 2, \mathrm{M0}$ ) undifferentiated nasopharyngeal carcinoma: a positive effect on progression-free survival. Int J Radiat Oncol Biol Phys 35: 463-469, 1996.

17. Chua DT, Nicholls JM, Sham JS, et al. Prognostic value of epidermal growth factor receptor expression in patients with advanced stage nasopharyngeal carcinoma treated with induction chemotherapy and radiotherapy. Int J Radiat Oncol Biol Phys 59: 11-20, 2004.

18. Hareyama M, Sakata $\mathrm{K}$, Shirato $\mathrm{H}$, et al. A prospective, randomized trial comparing neoadjuvant chemotherapy with radiotherapy alone in patients with advanced nasopharyngeal carcinoma. Cancer 94: 2217-2223, 2002. 
International Journal of Hematology and Oncology

19. Ma J, Mai HQ, Hong MH, et al. Results of a prospective randomized trial comparing neoadjuvant chemotherapy plus radiotherapy with radiotherapy alone in patients with locoregionally advanced nasopharyngeal carcinoma. J Clin Oncol 19: 13501357,2001

20. Baujat B, Audry H, Bourhis, et al. Chemotherapy in locally advanced nasopharyngeal carcinoma: an individual patient data meta-analysis of eight randomized trials and 1753 patients. Int J Radiat Oncol Biol Phys 64: 47-56, 2006.

21. Lee N, Laufer M, et al. Nasopharyngeal Carcinoma, Clinical Radiation Oncology, 3rd edition. Gunderson LL, Tepper JE, editors. Philadelphia: Elsevier press: P: 619-638, 2012.

22. Lok BH, Setton J. Nasopharynx. Perez CA, Halperin EC, Brady LW, editors. Principles and practice of radiation oncology, 6th ed. Philadelphia: Lippincott Williams \& Wilkins press: p: 730-760, 2013.

23. Al-Amro A, Al-Rajhi N, Khafaga $\mathrm{Y}$ et al. Neoadjuvant chemotherapy followed by concurrent chemo-radiation therapy in locally advanced nasopharyngeal carcinoma. Int J Radiat Oncol Biol Phys 62: 508-513, 2005.

24. To EW, Lai EC, Cheng JH, et al. Nasopharyngectomy for recurrent nasopharyngeal carcinoma: a review of 31 patients and prognostic factors. Laryngoscope 112: 1877-1882, 2002.

25. Gaspar C, Zapater E, Chust M, et al. Experience in the treatment of 98 carcinomas of the nasopharynx. Long-term followup and analysis of prognostic factors. Acta Otorrinolaringol Esp 51: 691-696, 2000.

26. Thompson L. World Health Organization classification of tumours: pathology and genetics of head and neck tumours. Ear Nose Throat J 85: 74, 2006.

\section{Correspondence:}

Dr. Hamit BASARAN

Hacettepe Üniversitesi

Radyasyon Onkolojisi Anabilim Dali

Sihhiye, ANKARA / TURKEY

Tel: (+90-543) 6076165

e-mail: drhbasaran@gmail.com 